\title{
Atrial gallop in coronary heart disease without overt infarction
}

\author{
H. J. N. Bethell ${ }^{1}$ and P. G. F. Nixon \\ From the Cardiac Department, Charing Cross Hospital, London
}

$A$ restrospective study was made of the apex cardiographic findings in patients with early coronary heart disease and in normal subjects, seen over a five-year period. Apex cardiograms had been performed on Io8 patients with coronary heart disease without evidence of previous myocardial infarction, hypertension, or valvular disease. There was an enlarged ' $a$ ' wave in $68(63 \%)$ cases. The resting electrocardiogram was abnormal in $27(25 \%)$. An enlarged ' $a$ ' wave was commoner in those with an abnormal resting electrocardiogram $(74 \%)$ than in those with a normal electrocardiogram (59\%). In the same five-year period, apex cardiograms were performed in 220 subjects without evidence of heart disease. An enlarged ' $a$ ' wave was found in 25 $(I I \%)$. Nineteen of these were followed up after an interval of 15 to 79 months (mean 36 months) and 8 were found to have no evidence of coronary heart disease.

In clinical practice, the early diagnosis of coronary heart disease is usually made from a history of angina pectoris or the finding of electrocardiographic abnormalities at rest or after exercise. It is traditional neither to expect nor to obtain much of importance from the examination of the heart sounds and pulsations.

The habit of examining all patients in the left lateral position (Bethell and Nixon, 1973a, b) has led us to believe that a large proportion of patients with early coronary heart disease have a palpable and audible atrial gallop, which may be recorded by the techniques of apex cardiography and phonocardiography. It is the purpose of this communication to present the results of these recordings in a series of patients with and without evidence of coronary heart disease. Also presented are the findings from follow-up examinations of apparently normal subjects who had presented an atrial gallop at first attendance.

\section{Subjects and methods}

A study was made of the notes and records of all patients with the diagnosis of coronary heart disease, but without evidence of previous myocardial infarction, who attended the Cardiac Department of the Charing Cross Hospital between I January 1966 and 3I December

Received 27 December 1973.

1 In receipt of a research fellowship from the Board of Governors of Charing Cross Hospital.
1970. The criteria for diagnosing coronary heart disease were:

I) The presence of a history of angina pectoris (World Health Organization, 1959).

2) The findings at first attendance, or developing within one year, of an abnormal electrocardiogram at rest (Blackburn et.al., 1960) and a history compatible with coronary heart disease, in the absence of evidence of other forms of heart disease.

3) The finding of an abnormal electrocardiogram after exercise - that is a flat or downward sloping ST segment depression of I $\mathrm{mm}$ or more, or lesser ST depression accompanied by multifocal ventricular ectopic beats.

Patients with valvular heart disease, evidence of cardiomyopathy, or signs of cardiac failure were excluded, as were those with hypertension (a systolic pressure exceeding $160 \mathrm{mmHg}$ or a diastolic pressure exceeding $90 \mathrm{mmHg}$ ) and those on treatment with hypotensive drugs.

A full history, physical examination, and 12-lead electrocardiogram had been taken in each case. In the majority of cases, a simultaneous apex cardiogram and phonocardiogram had been recorded, with the patient in the left lateral position. (It was the policy of the department to record apex cardiograms on patients with suspected coronary heart disease who had palpable apex beats, though this was not done in every case, usually because of problems of organization.) The recording apparatus has been described elsewhere (Nixon, Hepburn, and Ikram, 1964). In order to display the diastolic events most clearly, the whole record of the apex cardiogram was enlarged and the peak of systolic 


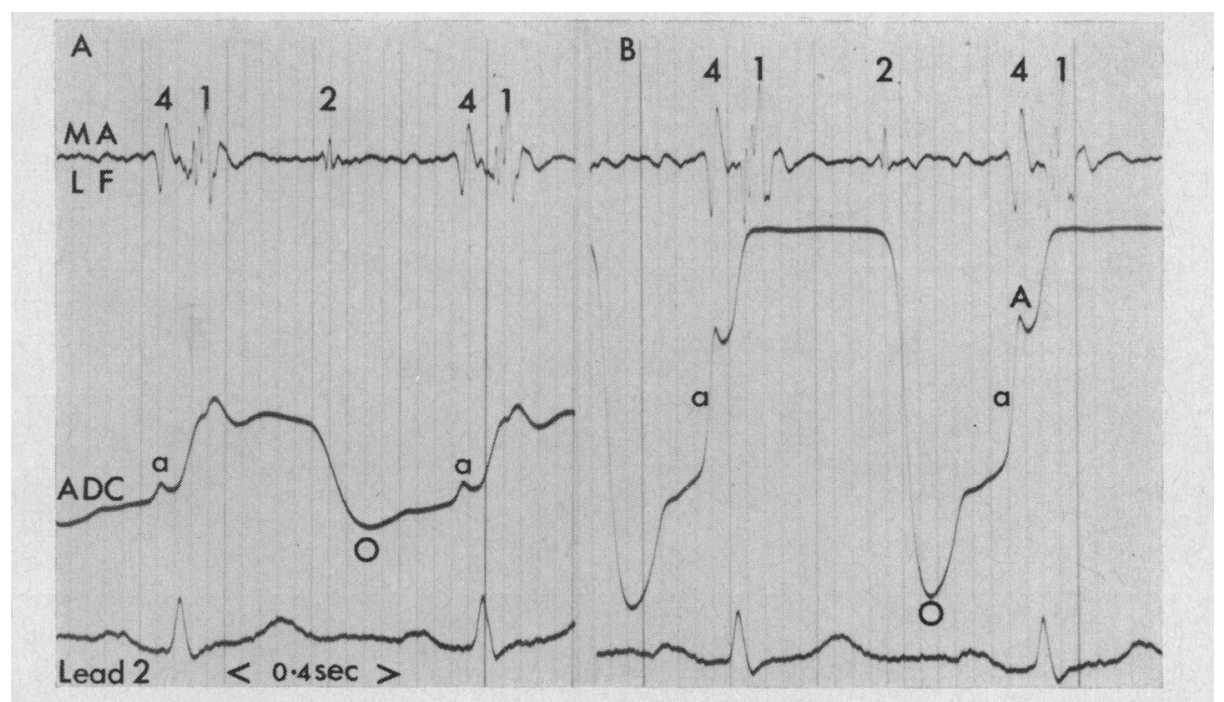

FI G. A) Apex cardiogram ( $A D C)$, mitral area low frequency phonocardiogram $(M A, L F)$, and lead II of the electrocardiogram in a patient with an enlarged ' $a$ ' wave and an atrial sound (4); B) The apex cardiogram has been amplified to display the diastolic events more clearly, and the peak of the systolic outward movement has been cut off. The height of the ' $a$ ' wave is measured as a percentage of the total diastolic excursion $(O-A)$.

outward movement cut off (Fig.). In each record the height of the atrial beat, the ' $a$ ' wave, was measured and expressed as a percentage of the total diastolic displacement (' $\mathrm{O}-\mathrm{A}$ '). The upper limit of normal was taken as 40 per cent (Taylor and Nixon, 1972).

A study was also made of the notes and records of all patients seen in the department over the same five-year period, I January I 966 to 3 I December 1970, who had no definite evidence of heart disease and who had had apex cardiograms and phonocardiograms performed. (It was not the policy of the department to record apex cardiograms and phonocardiograms on all normal subjects seen, and in most cases these subjects were those in whom it was desired to demonstrate normal heart movements and sounds or those without any diagnostic features of heart disease in whom coronary heart disease was suspected.) An attempt was made to follow up all those who had an enlarged ' $a$ ' wave at first presentation. In each follow-up case, a full history, physical examination, I2-lead electrocardiogram, and simultaneous apex cardiogram and phonocardiogram were performed. The subject was then exercised on a bicycle ergometer, with continuous electrocardiogram monitoring, to 75 per cent of his predicted maximum heart rate, and the electrocardiogram repeated after exercise.

\section{Results}

There were 159 patients who satisfied the criteria for coronary heart disease without previous myocardial infarction, of whom $120(75 \%)$ were men. The age range was 31 to 79 (mean 55). Of the 159 patients, the apex beat was recorded in the notes as being palpable in $134(84 \%)$, as impalpable in 14 $(9 \%)$, and there was no information about the apex in the remaining $1 \mathrm{I}(7 \%)$. Of the 134 with palpable apex beats, I08 had had apex cardiograms and phonocardiograms recorded. There was an abnormally large ' $a$ ' wave in $68(63 \%)$ of these, of whom the majority also had a clear atrial sound. Table I shows the number of patients, and the percentage with an enlarged ' $a$ ' wave in each ro-year age group. There was a tendency for the incidence of an abnormal ' $a$ ' wave to increase with age.

Out of 108 patients with apex recordings, the resting electrocardiogram was normal in 81 and abnormal in 27. Of the 8I with normal resting electrocardiograms, $48(59 \%)$, as opposed to 20 $(74 \%)$ of the 27 with abnormal resting electrocardiograms, had enlarged apical ' $a$ ' waves. This difference between the two groups is not statistically significant $(0.2>P>0 . I)$.

There were 72 patients with angina pectoris who had had apex recordings. In this group the resting electrocardiogram was abnormal in $12(17 \%)$, but there was an enlarged ' $a$ ' wave in $44(61 \%)$. There were 36 patients without angina who had had apex recordings and the resting electrocardiogram was abnormal in $15(38 \%)$ of these, but there was an enlarged ' $a$ ' wave in $24(67 \%)$.

Of the 36 patients without angina pectoris, 2I 
TABLE I Patients diagnosed as having early coronary heart disease who had had apex cardiograms recorded

\begin{tabular}{llllll}
\hline Age group & $30-39$ & $40-49$ & $50-59$ & $60+$ & Total \\
\hline No. of patients & 7 & 29 & 45 & 27 & 108 \\
No. with enlarged 'a' waves & $4(57 \%)$ & $15(52 \%)$ & $28(62 \%)$ & $21(78 \%)$ & $68(63 \%)$ \\
\hline
\end{tabular}

TABLE 2 Subjects without evidence of heart disease who had apex cardiograms recorded.

\begin{tabular}{lcccccc}
\hline Age group & $20-29$ & $30-39$ & $40-49$ & $50-59$ & $60+$ & Total \\
\hline No. of subjects & 45 & 58 & 66 & 41 & 10 & 220 \\
No. with enlarged 'a' waves & 0 & 0 & $10(15 \%)$ & $9(22 \%)$ & $6(60 \%)$ & $25(11 \%)$ \\
'Corrected' no. with enlarged 'a' waves & 0 & 0 & $9(14 \%)$ & $5(14 \%)$ & $3(43 \%)$ & $17(8 \%)$ \\
\hline
\end{tabular}

presented initially with normal resting electrocardiograms, i.e. they were diagnosed on the basis of electrocardiographic abnormalities after exercise, or resting electrocardiographic abnormalities developing within one year of first attendance. Of these $2 I$, $13(62 \%)$ had enlarged ' $a$ ' waves.

During the same 5-year period, 220 subjects aged 20 or more, without definite clinical or electrocardiographic evidence of heart disease, had apex cardiograms and phonocardiograms recorded in the Cardiac Department. Of these, 25 ( $11 \%$ ) had abnormally large ' $a$ ' waves: 24 of these were men. The average age was 52 (range 40 to 67). Table 2 shows the number of 'normal' subjects, and the percentage with an enlarged ' $a$ ' wave in each decade. The increasing incidence of an abnormal ' $a$ ' wave with age is pronounced. The follow-up results of these 25 subjects were: I) 3 could not be traced; 2) 2 were alive, but could not or would not attend: I had recently been admitted to another hospital with central chest pain, and his electrocardiogram showed ventricular ectopic beats, but no other abnormalities; 3) 2 had died: I of a postoperative pulmonary embolus, and a necropsy had shown an old inferior myocardial infarction which had not been recognized in life; the other patient had died of a cerebral tumour but no necropsy had been performed; 4) I 8 attended the Cardiac Department for follow-up histories and examinations, at an interval of 15 to 79 months (mean 36 months) from their initial attendance; the results for these subjects showed: I4 still had enlarged ' $a$ ' waves, of whom 4 had angina pectoris; of these 4 , one had an abnormal resting electrocardiogram, one had an abnormal electrocardiogram after exercise, and the remaining 2 had normal electrocardiograms at rest and after exercise, but one had become mildly hypertensive
$(160 / 100 \mathrm{mmHg})$; 10 did not have angina pectoris, and 2 of these had abnormal electrocardiograms after exercise; 4 now had normal sized ' $a$ ' waves: of these, none had angina pectoris, but one had an abnormal electrocardiogram after exercise.

Thus of 19 patients for whom full follow-up information was available, $8(42 \%)$ had evidence of coronary heart disease. Table 2 shows the incidence of abnormal ' $a$ ' waves in 'normal' subjects 'corrected' for the patients who later proved to have coronary heart disease. The effect of age on the incidence of enlarged ' $a$ ' waves is much less pronounced for this 'corrected' group.

\section{Discussion}

Angina pectoris and electrocardiographic changes, the traditional diagnostic criteria of coronary heart disease, appear relatively late in the course of the disease, and they have not proved useful in the prediction of myocardial infarction or sudden death (Gordon and Kannel, 1971). Such events usually occur in persons with long-standing coronary artery disease (Roberts, 1972) which may be well advanced even in the second and third decades of life (Enos, Holmes, and Beyer, 1953). Evidence of previous but unrecognized myocardial infarction is common in the victims of sudden death from coronary heart disease (Wikland, I97I). It is not unreasonable to suppose that these morbid anatomical abnormalities can cause left ventricular dysfunction before the stage of overt infarction or sudden death.

We believe that one of the earliest indicators of left ventricular dysfunction in coronary heart disease is the palpable and audible atrial gallop. It has been demonstrated in patients with angina pectoris, whether or not there was evidence of previous 
myocardial infarction (Benchimol and Dimond, 1962; Banks and Shugoll, 1967). The sign appears to depend upon impairment of early diastolic filling of the ventricle (Bethell and Nixon, 1973a).

Accentuation of the atrial beat in early coronary heart disease has been demonstrated by other techniques. Schweizer, Bertrab, and Reist (1965) found enlarged ' $a$ ' waves on the kinetocardiogram in 75 per cent of their patients with angina pectoris, and Rosa and Karsak (1960) found an abnormal end-diastolic pattern of the praecordial accelerogram in 49 per cent of their patients with coronary heart disease. Rosa et al. (1962) also found a higher incidence of end-diastolic abnormalities of the accelerogram in patients with angina pectoris and an abnormal electrocardiogram $(71 \%)$ than in patients with angina pectoris and a normal electrocardiogram $(41 \%)$. These figures are similar to our finding of an enlarged ' $a$ ' wave in 74 per cent of early coronary disease patients with an abnormal electrocardiogram and in 59 per cent with a normal electrocardiogram.

This study indicates that an enlarged apical ' $a$ ' wave is much more frequent than an abnormal resting electrocardiogram in early coronary heart disease. Moreover, the finding of an enlarged ' $a$ ' wave was the only clinical evidence of heart disease in a proportion of patients without angina pectoris or electrocardiographic abnormalities at rest. The sign of a palpable atrial beat correlates well with an enlarged apical ' $a$ ' wave (Epstein et al., 1968) and is quickly and safely elicited. Exercise electrocardiograms, however, are time consuming, require careful supervision, ideally including electrocardiographic monitoring during the exercise, and may be dangerous to the patient.

It is our experience that an enlarged ' $a$ ' wave of the apex cardiogram is an unusual finding in patients without evidence of heart disease. We could only trace 25 such cases seen over a five-year period, during which time apex cardiograms were performed in 220 adults with apparently normal hearts. This group cannot be considered as normal controls because the majority were referred to a cardiac department with suspected cardiovascular abnormalities, and it is likely that some had undetected heart disease. Other workers have also found enlarged ' $a$ ' waves to be relatively uncommon in apparently normal subjects (Edmands, 1966) and have proposed that it may be a sign of covert heart disease (Banks and Shugoll, 1967; Hill et al., 1969). The finding of evidence of coronary heart disease at follow-up in 8 of 19 'normal' subjects with enlarged ' $a$ ' waves suggests that this is true. However, it must be emphasized that those with normal sized ' $a$ ' waves were not followed up as controls, so the prognostic significance of an enlarged ' $a$ ' wave has not been proved. The incidence of an atrial sound increases with age in apparently normal subjects (Bethel and Crow, 1963; O'Rourke, 1970), and may be a physiological event in many cases (Benchimol and Desser, 197I; Spodick et al., I971), but the ' $a$ ' wave size has been found not to increase with age in apparently normal subjects (Dimond, Duenas, and Benchimol, 1966; Edmands, 1966; Ginn et al., 1967). Though the initial figures in our series of normal subjects suggested that the incidence of an enlarged ' $a$ ' wave increased with age, follow-up examination of these subjects revealed that a large proportion of the older patients had heart disease. The corrected figures (Table 2) show little age variation. The recovery of a normal ' $a$ ' wave size by some of the follow-up group is an interesting finding. Some may have had a transient myocarditis, and others may have suffered ischaemic myocardial injury from which they had recovered (one had an abnormal electrocardiogram after exercise). The high incidence of old unrecognized myocardial infarction in the victims of sudden death (Wikland, 197I) indicates that coronary heart disease is more commonly present than diagnosed.

Where an atrial gallop is caused by left ventricular dysfunction, in the absence of clinically obvious heart disease or hypertension, the most likely cause is coronary heart disease since other forms of myocardial disease are comparatively rare in the U.K. Further study, including a long-term prospective community survey, will be needed to clarify the significance of the lone atrial gallop, and to determine whether or not it may be a physiological event in some cases. Our findings suggest that the clinical and instrumental detection of the palpable atrial gallop will prove a more reliable screening test for coronary heart disease than the resting electrocardiogram.

We wish to thank Miss Anne Smith and Miss Irene Wood of the Electrocardiograph Department of the Charing Cross Hospital for their invaluable help.

\section{References}

Banks, T., and Shugoll, G. I. (1967). Confirmatory physica 1 findings in angina pectoris. Fournal of the American Medical Association, 200, 1031.

Benchimol, A., and Desser, K. B. (1971). The fourth heart sound in patients with proven normal hearts (abstract). Circulation, 44, Suppl. 2, 140.

Benchimol, A., and Dimond, E. G. (1962). The apex cardiogram in ischaemic heart disease. British Heart fournal, 24, 581 .

Bethel, C. S., and Crow, E. W. (1963). Heart sounds in the aged. American fournal of Cardiology, 11, 763.

Bethell, H. J. N., and Nixon, P. G. F. (1973a). Understanding the atrial sound. British Heart fournal, 35, 229. 
Bethell, H. J. N., and Nixon, P. G. F. (1973b). The examination of the heart in the supine and left lateral positions. British Heart fournal, 35, 902.

Blackburn, H., Keys, A., Simonson, E., Rautaharju, P., and Punsar, S. (1960). The electrocardiogram in population studies. Circulation, 21, r160.

Dimond, E. G., Duenas, A., and Benchimol, A. (1966). Apex cardiography. American Heart Fournal, 72, I24.

Edmands, R. E. (1966). An assessment of the utility of the resting apex cardiogram in the epidemiology of cardiovascular disease. American fournal of Cardiology, 17, 180.

Enos, W. F., Holmes, R. H., and Beyer, J. (1953). Coronary disease among United States soldiers killed in action in Korea. Fournal of the American Medical Association, 152, I090.

Epstein, E. J., Coulshed, N., Brown, A. K., and Doukas, N. G. (1968). The ' $a$ ' wave of the apex cardiogram in aortic valve disease and cardiomyopathy. British Heart fournal, 30, 591.

Ginn, W. M., Sherwin, R. W., Harrison, W. K., and Baker, B. M. (1967). Apex cardiography: use in coronary heart disease and reproducibility. American Heart fournal, 73, 168.

Gordon, T., and Kannel, W. B. (197I). Premature mortality from coronary heart disease. The Framingham Study. fournal of the American Medical Association, 215, 1617.

Hill, J. C., O'Rourke, R. A., Lewis, R. P., and McGranahan, G. M. (1969). The diagnostic value of the atrial gallop in acute myocardial infarction. American Heart fournal, 78, I94.

Nixon, P. G. F., Hepburn, F., and Ikram, H. (1964). Simultaneous recording of heart pulses and sounds. British Medical fournal, $\mathbf{1}, 1169$.

O'Rourke, R. A. (1970). The atrial sound. Factors regulating its occurrence and timing. American Heart fournal, 80, 715.
Roberts, W. C. (1972). Coronary arteries in fatal acute myocardial infarction. Circulation, 45, 215.

Rosa, L. M., Constantino, J. P., Karsak, N., Reich, R., and Zezmer, B. (1962). The precordial accelerogram in ischemic heart disease. A study of middle-aged and old patients with angina pectoris; recent and old myocardial infarction. American fournal of Cardiology, 9, 534.

Rosa, L. M., and Karsak, N. (1960). Precordial pulsatory mechanism in coronary heart disease (abstract). Circulation, 22, 801.

Schweizer, W., Bertrab, R. V., and Reist, P. (1965). Kinetocardiography in coronary artery disease. British Heart fournal, 27, 263.

Spodick, D. H., Rectra, E., Khan, A., and Pigott, V. (197I). Audibility of the fourth heart sound: a prospective, blinded investigation (abstract). Circulation, 44, Suppl. 2, 33.

Taylor, D. J. E., and Nixon, P. G. F. (1972). Assessment of left ventricular function after myocardial infarction. British Heart fournal, 34, 905.

World Health Organization (1959). Expert committee on cardiovascular disease and hypertension. Hypertension and coronary heart disease: classification and criteria for epidemiological studies. World Health Organization. Technical Reports Series, I68. World Health Organization, Geneva.

Wikland, B. (I97I). Medically unattended fatal cases of ischaemic heart disease in a defined population. Acta Medica Scandinavica, Suppl. 524.

Requests for reprints to Dr. P. G. F. Nixon, Cardiac Department, Charing Cross Hospital, Fulham Palace Road, London W6 8RF. 